\title{
CAPÍTULO 05
}

\section{A IMPORTÂNCIA DA RUGOSCOPIA PALATINA NA IDENTIFICAÇÃO DE CADAVERES HUMANOS: UMA REVISÃO DE LITERATURA}

DOI 10.4322/978-65-995353-2-1.c05

Erick Lúcio Souza Santos ${ }^{1}$, Thalita Oliveira da Silva Borba ${ }^{2}$, Letícia Rafaella Marinho Honorato ${ }^{3}$, Anne Caroline Silva Freire de Sá ${ }^{4}$, Alícia Lima de Lira ${ }^{5}$, Jadson da Silva Santana ${ }^{6}$, André Almeida Antunes ${ }^{7}$, Arthur Mendes Lima $^{8}$, Fernanda Maria Matos Aragão de Souza', Mr. Rafael de Sousa Carvalho Saboia ${ }^{10}$

${ }^{1}$ Centro Universitário Tabosa de Almeida ASCES, UNITA, (ErickLucioEL@Gmail.com) ${ }^{2}$ Centro Universitário Tabosa de Almeida ASCES-UNITA, (Thalita.borba00@gmail.com) ${ }^{3}$ Centro Universitário Tabosa de Almeida ASCES-UNITA, (leticiamarinhoh@ hotmail.com)

${ }^{4}$ Centro Universitário Tabosa de Almeida ASCES-UNITA, (annecarolinefreiree@gmail.com)

${ }^{5}$ Centro Universitário Tabosa de Almeida ASCES-UNITA, (alicialimadl@gmail.com) ${ }^{6}$ Universidade Federal de Pernambuco UFPE, (jadsonufpe@gmail.com) ${ }^{7}$ Centro Universitário de Belo Horizonte Unibh, ( $\underline{\text { andredemu@yahoo.com.br) }}$

${ }^{8}$ Universidade Federal de Juiz de Fora, (arthurmlima_@ hotmail.com)

${ }^{9}$ Centro Universitário Tabosa de Almeida ASCES-UNITA, (aragaofernanda22@gmail.com) ${ }^{10}$ Centro Universitário Tabosa de Almeida ASCES-UNITA, (rafaelsaboia@ asces.edu.br)

\section{Resumo}

Objetivo: Realizar uma revisão literária em relação a importância da rugoscopia palatina na identificação de cadáveres e sua aplicabilidade. Metodologia: Trata-se de uma Revisão de Literatura com busca de artigos científicos disponíveis no BIREME, Google Acadêmico, SciELO, Science Direct e PubMed. Na seleção dos estudos, foram elencados como critérios de inclusão, para posterior análise e seleção, artigos publicados no período entre 2015 e 2021, nos idiomas inglês, português e espanhol, os quais abordavam os temas associados a Odontologia Legal e à Identificação de Cadáveres, dos quais 24 foram selecionados. Resultados: Através do conhecimento de que cada ser humano é único e que há necessidade de distinção dentre eles para confirmação de identidade em determinadas situações como a de identificação de cadáver, é necessária a utilização de diversas metodologias e técnicas da área forense. Tais técnicas Pesquisa e Extensão 
utilizam como banco de dados, materiais do indivíduo armazenados anteriormente, para análise e comparação com as características individuais do cadáver, realizando a identificação do corpo de maneira fidedigna. Contudo, com o Objetivo de se obter uma maior probabilidade de sucesso nas técnicas forenses, elas devem cumprir alguns fundamentos inalteráveis, sendo eles: a "Individualidade", a "Imutabilidade", a "Perenidade", a "Praticabilidade" e a "Classificabilidade". A rugoscopia palatina, é definida como o estudo e análise das rugas presentes no palato, é um método alternativo utilizado quando há inviabilização de identificação corporal (Ex. Carbonização) por técnicas convencionais, pois as rugas possuem alta resistência a temperatura e são classificadas como uma das características que compõe a identidade genética do indivíduo, por serem intransferíveis e únicas. Considerações Finais: A rugoscopia palatina é uma técnica de fácil acesso e de baixo custo, possuindo grande aplicabilidade. Contudo há à necessidade de o dentista realizar de forma adequada o armazenamento dos dados (Ex.: Radiografias, Moldagens, Fotos) para possíveis necessidades.

Palavras-chave: Rugoscopia Palatina; Identificação Humana; Odontologia Forense; Palatal Rugoscopy.

Área Temática: Ciências da Saúde

E-mail do autor principal: ErickLucioEL@Gmail.com

\section{INTRODUÇÃO}

A humanidade possui uma gama de atributos, diferenciando-se entre si mesmos por meio de características únicas, como impressões digitais, as pregas palatinas e até mesmo o Ácido desoxirribonucleico (DNA). Sendo de extrema importância tais particularidades para diferenciação e reconhecimento de cadáveres ou seres humanos vivos por meio de técnicas singulares (TORRES, et al. 2021; ARGOLLO, et al. 2017).

Em pleno Século XXI, eventualidades que provocam perdas de estruturas, carbonização de corpos e desfigurações apresentam um índice alto na sociedade, como acidentes automobilísticos, assaltos e assassinatos, diversas vezes inviabilizando o reconhecimento de cadáveres. Fazendo-se necessária a implementação de ferramentas e metodologias cujo seja possível analisar e reconhecer as individualidades dos cadáveres de forma eficaz (BARROS, 2017; BASAURI, 1961).

Nos dias atuais, uma das áreas responsável por analisar e reconhecer cadáveres humanos é a Odontologia Legal, realizando métodos comparativos de achados ósseos do indivíduo a registros odontológicos armazenados, como modelos de gesso das arcadas, radiografias e até mesmo fotografias. Contudo, em casos em que há uma acentuada perda de estrutura óssea ou dos elementos dentários das arcadas, faz-se necessário o emprego de técnicas que avaliam 
estruturas formadas por tecidos moles (DA PAIXÃO ARGOLLO, et al. 2017; DAS NEVES, 2021).

Um método de identificação alternativo e eficaz na odontologia forense é a rugoscopia palatina, cujo foco de estudo são as pregas palatinas através da análise do formato, posição e tamanho das mesmas. Tal método é aplicado quando a datiloscopia, análise dos arcos dentários e/ou o exame de DNA não conseguem entregar resultados conclusivos (DOS SANTOS, et al. 2021; CORREIA, et al. 2019).

As rugas/pregas palatinas encontram-se no terço anterior do palato, sendo compostas por tecido conjuntivo fibroso encontrado entre a formação óssea da região palatina e um epitélio escamoso de revestimento. Tal formação tem características assimétricas, irregulares e únicas e imutáveis durante toda a vida do ser humano, tornando-as viáveis para identificação e diferenciação de cadáveres. Sua aplicabilidade é de maneira abrangente como na antropologia, genética, anatomia e na odontologia legal (JEDDY; RAVI; RADHIKA, 2017; FURLAN, et al. 2016).

A análise e identificação de cadáveres é uma das áreas cujo a odontologia possui o direito de exercer e atuar de forma legal, tendo como função o presente trabalho destacar a importância de um método alternativo de identificação humana na atualidade.

\section{METODOLOGIA}

Este estudo trata-se de uma Revisão de Literatura realizada através da busca de artigos científicos disponíveis nas bases de dados BIREME, Google Acadêmico, SciELO, Science Direct e PubMed. Os descritores de busca foram: "Rugoscopia Palatina", "Identificação Humana", "Odontologia Forense" e "palatal rugoscopy”. A tática de busca ampla, incluindo diversos descritores e combinações entre esses, teve como objetivo encontrar estudos a respeito da Rugoscopia Palatina como método de identificação humana. Na seleção dos estudos, foram elencados como critérios de inclusão, para posterior análise e seleção, artigos publicados no período entre 2015 e 2021, nos idiomas inglês e português, os quais abordavam os temas associados a Odontologia Legal e à Identificação de Cadáveres. Devido à natureza do tema, decidiu-se incluir na busca artigos originais, revisões de literatura, editoriais e relatos de experiência publicados em periódicos científicos.

\section{RESULTADOS}

E - book Tripé do Ensino Superior: Ensino, Pesquisa e Extensão 
A Odontologia Legal é uma especialidade odontológica que tem como um dos objetivos a identificação de cadáveres. Através do conhecimento de que cada ser humano é único e que há necessidade de distinção dentre eles para confirmação de identidade em determinadas situações como a de identificação de cadáver, é necessária a utilização de diversas metodologias e técnicas da área forense. Tais técnicas utilizam como banco de dados, materiais do indivíduo armazenados anteriormente, para análise e comparação com as características individuais do cadáver, realizando a identificação do corpo de maneira fidedigna (LIMA; MEDEIROS, 2015; LIMA M.V.F.N, et al, 2016).

Com o Objetivo de se obter uma maior probabilidade de sucesso nas técnicas forenses, elas devem cumprir alguns fundamentos inalteráveis, sendo eles a "Individualidade", cuja definição é ter a unicidade entre os demais indivíduos, possibilitando a identificação, a "Imutabilidade", sendo essa a inalteração ou modificação da estrutura através do tempo, a "Perenidade", longevidade da estrutura ao longo do tempo, a "Praticabilidade", devendo ser viável tanto para comparação das estruturas quanto de maneira financeira, e a "Classificabilidade", sendo por fim esta a organização e armazenamento dos dados para posterior utilização (TORRES, et al. 2021; MODESTO;JUNIOR FIGUEIRA, 2017; MATUTE, 2015).

A odontologia forense utiliza como principal método de identificação humana os arcos da maxila e mandíbula, tanto pela presença de diversas estruturas que auxiliam na análise do corpo quanto pela possiblidade de utilizá-los mesmo sem a presença de tecidos moles. Contudo, tal método torna-se inviabilizado em casos em que não há estruturas dentárias para análise e identificação, sendo necessária a aplicação de métodos alternativos, como o estudo das rusgas palatinas (VANRELL, 2019; SHETTY, et al, 2016).

As rugas Palatinas começam a ser desenvolvidas terceiro mês de vida intrauterina do feto adjunto ao desenvolvimento da "identidade biológica", onde sua especificidade corporal inicia-se. Uma das características benéficas das rugosidades palatinas é sua localização na região anterior do palato, composto por mucosa corrugada por um conjunto de pregas ligadas ao plano ósseo subjacente, local que as protege tanto de traumas quanto de altas temperaturas. Elas possuem em sua constituição tecido conjuntivo fibroso e denso da submucosa revestindo o osso e algumas vezes sendo confundido com o periósteo (BARROS, 2017; VANRELL,2019; SILVA, A. V., et al, 2020). 
As rugas palatinas foram classificadas incialmente por Carrea (1937), cujo considerava a orientação bilateral das rugosidades, diferente de Martins dos Santos(1946), autor da classificação de maior relevância na odontologia forense da atualidade, cujo estudo fundamenta-se na localização de cada rugosidade de acordo com a posição e possui quatro divisões, a "ruga inicial" (localizada mais anteriormente do lado direito da rafe palatina mediana), as "rugas complementares" (encontradas do lado direito da rafe palatina mediana), a "ruga subinicial" (situada de forma mais anterior possível ao lado esquerdo da rafe palatina mediana), e por fim as "rugas subcomplementares" (posicionadas ao lado esquerdo da rafe palatina mediana) (MARTINS DOS SANTOS, 1946; CARREA, 1937).

A rugoscopia palatina, é definida como o estudo e análise das rugas presentes no palato do ser humano como o nome sugere. Elas são classificadas quanto a posição, forma, tamanho e quantidade, tais particularidades são examinadas e empregadas como pilares para a identificação humana, que possui um protocolo padronizado a ser seguido para análise forense: análise da arcada dentária; inspeção da região oral; avaliação dos registros odontológicos prévios e por último o exame "odontolegal", cujo define-se como um exame minucioso final. Tal técnica tem como vantagens sua aplicabilidade, podendo ser empregada em situações de carbonização corporal total, comprometendo a região oral e face, sem presença de elementos dentários que permitam a identificação (CARREA, 1920; GARBIN; AMARAL; GRECHI, 2017; MARTINS DOS SANTOS, 1946).

Desse modo, a técnica empregada de rugoscopia palatina é um método alternativo, mas seguro, de identificação de cadáveres. Definido como um método comparativo da estrutura palatina do cadáver com os documentos armazenados prévios (Ex. moldagens, radiografias e fotos), cujo possua uma cópia da estrutura em questão (KAUR, 2021; MANGANOTTI,2021; SILVA, F. L. M., et al, 2019).

\section{CONSIDERAÇÕES FINAIS}

O estudo dos elementos dentários, de exames laboratoriais do DNA e a análise de impressões digitais são métodos de identificação humana com propriedades de serem de fácil acesso, seguros e de baixo custo. A identificação humana é realizada diariamente por meio de métodos corriqueiros que se passam despercebidos na população, como a necessidade de RG, $\mathrm{CNH}$, entre outros documentos com foto. Contudo, há ocorrências onde tais metodologias não são possíveis, necessitando de uma análise mais especifica, denominada "identidade biológica",

\section{E - book Tripé do Ensino Superior: Ensino,} Pesquisa e Extensão 
na qual a rugoscopia palatina destaca-se em situações de carbonização do corpo e ausência de arcada dentária no individuo, pois as rugas são resistentes a altas temperaturas.

Porém para efetiva utilização de tais métodos, faz-se necessária a colaboração do Cirurgião-Dentista para realizar a conservação de tais dados de maneira apropriada. Pois não é rotina de muitos dentistas realizarem o armazenamento correto de moldagens, radiografias e fotografias dos pacientes, inviabilizando a utilização da técnica, não por sua complexidade, mas pela falta do cuidado com métodos de armazenagem de dados. Mesmo com tais dificuldades a técnica apresentada possui um potencial enorme de aplicabilidade na identificação humana.

\section{REFERÊNCIAS}

Argollo, S. D. P., Argollo, B. P., Argollo, P. A. N., \& Marques, J. A. M. Utilização da rugoscopia palatina para identificação de corpo carbonizado: Relato de caso pericial. Revista Brasileira de Odontologia Legal, v.4, n.1, p. 107-113, 2017.

BARROS, Izabelle Remígio. A importância da análise da rugoscopia palatina na Odontologia legal. Acta de Ciências e Saúde, v. 2, n. 1, p. 1-13, 2017.

Basauri, C. Forensic odontology and identification. Int Crim Police Rev, v.16, 45-51, 1961.

Carrea JU. La Identificacion humana por las rugosidades palatinas. Rev Orthodont, v.1, p.323, 1937.

Carrea, JU. Ensayos Odontométricos [tese]. Buenos Aires: Universidade Nacional de Bueno Aires, 1920.

CORREIA, A. D. M., BARBOSA, D. D. S., ALCÂNTARA, J. A. D. S., FONTENELE, E. H. L., BEZERRA, T. P. Importância do registro das ausências dentais para a identificação humana: relato de caso. Rev. Bras. Odontol. Leg. RBOL, p 82-89, 2019.

DA PAIXÃO ARGOLLO, Selma et al. Utilização da rugoscopia palatina para identificação de corpo carbonizado-relato de caso pericial. Revista Brasileira de Odontologia Legal, v. 4, n. $1,2017$.

DAS NEVES, Isabelle Silva Ramos et al. Rugoscopia palatina e seus desafios na identificação humana: uma revisão integrativa. Research, Society and Development, v. 10, n. 4, p. e23810414090-e23810414090, 2021.

E - book Tripé do Ensino Superior: Ensino, Pesquisa e Extensão 
DOS SANTOS, Anderson Nobrega et al. A Queiloscopia como técnica de identificação humana: Uma revisão sistemática da literatura. Research, Society and Development, v. 10, n. 8, p. e50110817401-e50110817401, 2021.

FURLAN, A. C. K., Nogueira, B. S., DEMETRIO, A. T. W., \& LOLLI, L. F. Validação do método de carrea na região noroeste do estado do Paraná, Brasil. Revista Brasileira de Odontologia Legal, v.3, n. 1, p. 15-23, 2016.

GARBIN, C. A. S., AMARAL, M. A., GREGHI, R. S. S. Análise e classificação da rugosidade palatina em uma população brasileira. Revista Brasileira de Odontologia Legal - RBOL, v. 4, n. 3, p. 48-56, 2017.

JEDDY, Nadeem; RAVI, Shivani; RADHIKA, T. Current trends in forensic odontology. Journal of forensic dental sciences, v. 9, n. 3, p. 115, 2017.

KAUR, Avineet et al. Palatoscopy (Rugoscopy) assistance in forensic investigations. IP International Journal of Forensic Medicine and Toxicological Sciences, v. 6, n. 2, p. 31$35,2021$.

Lima MVFN, Costa GM, Silva VB, Nascimento MR, Moraes HH, Lucena EES. Verificação da praticabilidade e da unicidade na queiloscopia e na palatoscopia como métodos de identificação humana. Rev Bras Odontol Leg RBOL, v.3, n.1, p. 5-14, 2016.

LIMA, Hassan Lavalier de Oliveira; MEDEIROS, Urubatan Vieira de. Aplicabilidade do DNA em odontologia forense. Odontologia Clínico-Científica (Online), v. 14, n. 4, p. 801$808,2015$.

MANGANOTTI, Ana Beatriz Manetti et al. Análise e classificação da rugosidade palatina em um grupo de jovens adultas brasileiras. Research, Society and Development, v. 10, n. 1, p. e46810111743-e46810111743, 2021.

MARTINS-DOS-SANTOS, G. Ficha Odonto-Rugopalatina. Revista Brasileira de Odontologia, v. 4, n. 1, p. 36-42, 1946.

Matute, G. A. R. La rugoscopia palatina forense como método de identificación humana a través del análisis comparativo. Revista Científica de la Escuela Universitaria de las Ciencias de la Salud, v.2, n.1, p. 37-42, 2015. 
MODESTO, Tayline de Oliveira Paiva; JUNIOR, Enio Figueira. Identificação humana através da Rugoscopia Palatina. Revista Interdisciplinar do Direito-Faculdade de Direito de Valença, v. 11, n. 2, 2017.

Shetty D, Anshi Jain AJ, Khanna KS, Amit Gupta NP, Chowdhary M. Assessment of palatal rugae pattern and their reproducibility for application in forensic analysis. J Forensic Dent Sci. v.5, n.2, p. 106-9, 2016.

Silva, A. V., Costa, A. L. P., Silva, M. L. C. A., Oliveira, M. B., Paranhos, L. R., Franco, A. Marques, J. A. M., \& Musse, J. Estudo anatômico do padrão labial entre mães e filhas do Nordeste brasileiro. Research, Society and Development, v.9, n.11, 2020.

Silva, F. L. M., Antunes, A. A., Carvalho, M. V. D., Soriano, E. P., Saboia, R. S. C., \& Porto, G. G. Avaliação do padrão morfológico de rugoscopia palatal em uma população brasileira.

Revista Brasileira de Odontologia Legal, v.6, n.2, p. 2-12, 2019.

TORRES, José Lucas Medeiros et al. A APLICABILIDADE DA RUGOSCOPIA PALATINA NO PROCESSO DE IDENTIFICAÇÃO HUMANA POST MORTEM EM ODONTOLOGIA LEGAL. Jornada Odontológica dos Acadêmicos da Católica, v. 6, 2021.

VANRELL, J.P. Odontologialegal\&Antropologiaforense, 3.ed., Rio de Janeiro: Guanabara Koogan, 2019. 